\title{
ANALISIS PROBABILITAS KESTABILAN LERENG TAMBANG TIMAH PRIMER BLOK PEMALI, BANGKA, INDONESIA
}

\author{
Teguh Nurhidayat ${ }^{1}$, Edo Syawaludin ${ }^{1)}$, Muchtar Arifin ${ }^{1)}$ dan Iwan Oktariansyah ${ }^{1)}$ \\ ${ }^{1)}$ PT. TIMAH, Tbk.
}

\begin{abstract}
ABSTRAK
Studi geoteknik sangat penting pada tambang terbuka untuk menentukan geometri lereng dan kestabilan lereng tambang. Kestabilan lereng pada tambang terbuka sangat mempengaruhi kelangsungan produksi dan keselamatan pekerja pada tambang tersebut. Pada kasus tambang timah primer, material pembentuk lereng yang terdiri dari batuan induk berupa granit dan tanah dekomposisi dari granit. Hal ini dapat memberikan masalah dalam penentuan parameter kekuatan material dan analisis yang digunakan. Karena parameter kekuatan yang berasal dari dekomposisi granit mempunyai variabilitas yang tinggi. Metode deterministik tidak cukup untuk memodelkan kestabilan lereng pada tambang timah primer. Sehingga dilakukan perpaduan antara penggunaan metode deterministik dan probabilistik dalam proses analisis kestabilan lereng. Pemboran geoteknik dilakukan dengan cara full coring. Parameter sifat fisik dan mekanik material lereng didapat dari hasil pengujian laboratorium. Nilai internal shear angle, unit weight dan cohesion diproses dengan simulasi Monte Carlo sebagai model variabel acak. Simulasi Monte Carlo melakukan evaluasi secara simultan dari kestabilan lereng. Simulasi juga dilakukan dengan variasi sudut lereng keseluruhan dan proses pengeringan air tanah. Hasil simulasi memperlihatkan lereng pada penampang 1 dengan sudut lereng keseluruhan sebesar $25^{\circ}$ (pada keadaan dinamik, $\mathrm{SF}=$ $1.216, \mathrm{PF}=8.1 \%, \mathrm{RI}=1.419$ ) dengan proses pengeringan air tanah, penampang 2 pada sudut lereng keseluruhan $35^{\circ}$ (pada keadaan dinamik, $\left.\mathrm{SF}=1.44, \mathrm{PF}=0 \%, \mathrm{RI}=3.535\right)$ dan Penampang 3 pada sudut lereng keseluruhan $15^{\circ}$ (pada keadaan dinamik, $\mathrm{SF}=1.469, \mathrm{PF}=13.7 \%, \mathrm{RI}=1.079$ ).
\end{abstract}

Kata kunci: kestabilan lereng, probabilitas, timah primer

\begin{abstract}
Geotechnical studies are very important in open pit mining to determine the slope geometry and stability of the mine slope. Slope stability at an open pit greatly influences the continuity of production and the safety of workers at the mine. In the case of primary tin mining, slope-forming material consisting of host rock in the form of granite and soil decomposition of granite. It can give problems in determining the strength parameters and the modeling used. Because the strength parameters derived from granite decomposition have high variability. The deterministic method is not enough to model slope stability in primary tin mines. So it is a combination of the use of deterministic and probabilistic methods in the process of modeling the slope stability. Geotechnical drilling is done by full coring. The parameters of physical and mechanical properties of slope material are obtained from laboratory test results. Internal shear angle, unit weight and cohesion values are processed by Monte Carlo simulation as a random variable model. Monte Carlo simulations carry out simultaneous evaluations of slope stability. Simulations are also carried out with overall slope angle variation and groundwater dewatering. Simulation results show that the slope at cross-section 1 at overall slope angle(OSA) $25^{\circ}$ (under dynamic condition, $S F=1,216, P F$ $=8.1 \%, R I=1,419)$ with groundwater dewatering process, cross-section 2 at with $35^{\circ}(O S A)(S F=$ 1.44, $P F=0 \%, R I=3,535)$ and Section 3 at $15^{\circ}(S F=1,469, P F=13.7 \%, R I=1,079)$.
\end{abstract}

Key word: slope stability, probability, primary tin 


\section{A. PENDAHULUAN}

Tambang Pemali adalah salah salah satu tambang timah primer yang berada didalam IUP PT. Timah Tbk dan terletak di Bangka Utara, Kepulauan Bangka Belitung. Daerah Pemali secara morfologi memiliki topografi bergelombang dengan kenampakan berupa bukit-bukit kecil yang memiliki ketinggian 40-60 mdpl. Lokasi tambang timah primer yang ada di Pemali dahulu merupakan sebuah bukit. Karena proses penambangan open pit, morfologi bukit tersebut menjadi hilang. Tambang Pemali sempat berhenti beroperasi karena faktor ekonomi yang tidak menguntungkan. Pada tahun 2012, Tambang Pemali dioperasikan kembali dengan kondisi pit yang terendam air sehingga dibutuhkan waktu untuk proses pengeringan. Sehingga dilakukan proses studi kelayakan dilakukan untuk membuat desain Tambang Pemali yang baru, khususnya geoteknik.

Kajian geoteknik dalam hal kestabilan lereng tambang merupakan aspek yang sangat penting dalam menunjang aktivitas penambangan. Faktor kestabilan lereng menjadi faktor yang harus diperhatikan dengan serius. Karena desain yang tepat akan berdampak besar pada keekonomian tambang. (Nurhidayat, 2016)

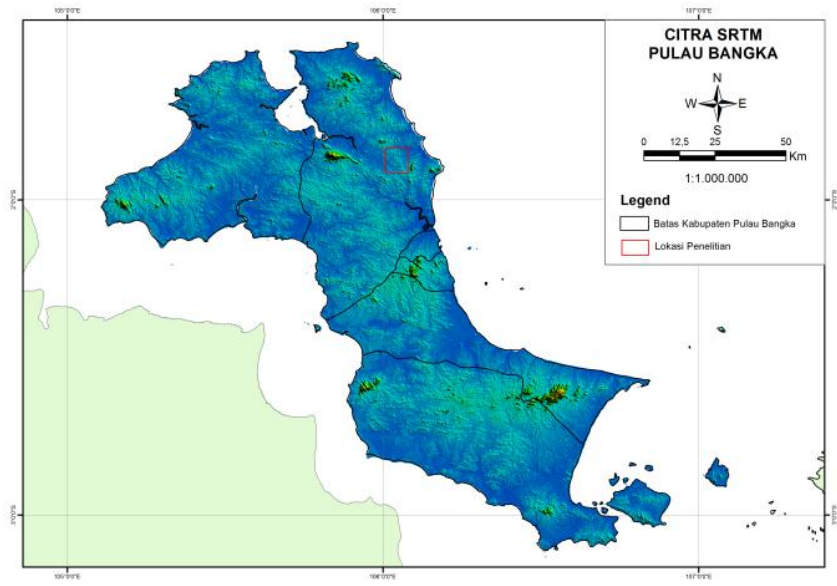

Gambar 1. Lokasi site Pemali Kabupaten Bangka Utara

\section{Geologi Regional}

Sebagian besar wilayah penelitian berada pada formasi Granit Klabat. Formasi Granit Klabat merupakan formasi yang disusun oleh granit, granodiorit, adamalit dan diorit kuarsa. Setempat dijumpai retas aplit dan pegmatit. Batuan granit tersebut terkekarkan dan tersesarkan dan menerobos formasi Diabas Penyabung. Umur dari hasil analisa radiometri menunjukkan umur 217\pm 5juta tahun atau berumur Trias Akhir (Mangga \& Djamal, 1994)

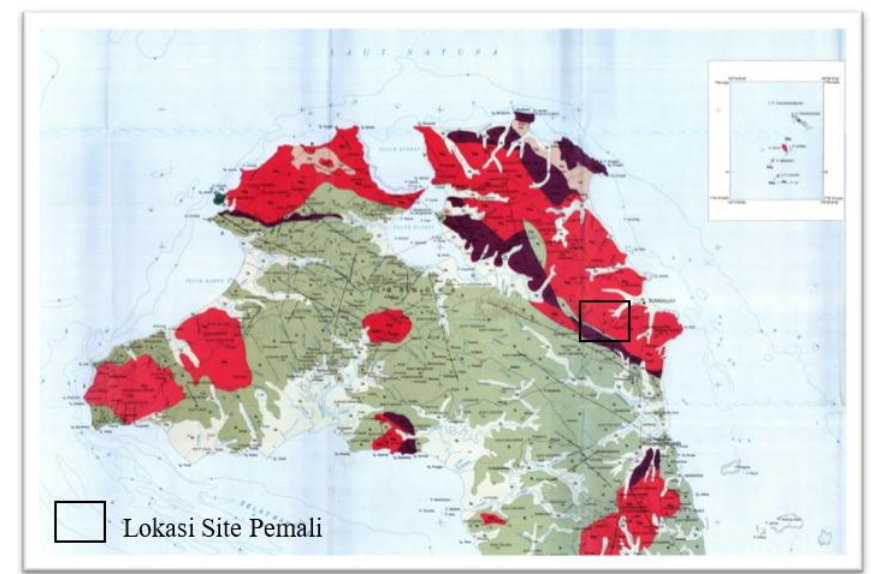

Gambar 2. Peta Geologi Reginal Bangka Utara (dimodifikasi dari Mangga \& Djamal, 1994) 
Formasi Diabas Penyabung merupakan formasi yang terdiri dari diabas yang terkekarkan dan tersesarkan. Formasi ini menerobos Kompleks Malihan Pemali (CPp). Umurnya diperkirakan Permian. Formasi Tanjunggenting merupakan formasi yang terdiri dari perselingan batupasir malik, batupasir, batupasir lempungan dan batulempung dengan lensa batugamping. Setempat dijumpai oksida besi. Formasi ini berlapis baik, terlipat kuat, terkekarkan dan tersesarkan dengan tebal berkisar antara $250-150 \mathrm{~m}$. Di dalam batugamping dijumpai fosil Montlivaultia molukkana, Peronidella, Entrochus sp., dan Encrinus sp yang berumur Trias dengan lingkunagn pengendapan yang diperkirakan laut dangkal, Formasi ini diterobos oleh Granit Klabat dan menindih tak selaras Kompleks Pemali (CPp). (Mangga \& Djamal, 1994)

Kompleks Pemali (CPp) terdiri dari batuan filit dan sekis dengan sisipan kuarsit dan lensa batugamping. Formasi ini terkekarkan, terlipat, tersesarkan, dan diterobos oleh Granit Klabat. Pada formasi ini dijumpai fosil berumur Permian pada batugamping di dekat Air Duren, sebelah selatantenggara Pemali. Umur satuan diduga Permian dengan lokasi tipe di daerah Pemali. Pada sebagian kecil site ini dijumpai juga Alluvium yang tersusun dari bongkah, kerakal, kerikil, pasir, lempung dan gambut. Formasi ini berumur Kuarter. (Mangga \& Djamal, 1994

\section{Kestabilan Lereng}

Menurut (Zakaria, 2009) Dalam Nurhidayat, (2016) Lereng yang alami ataupun lereng buatan memiliki nilai kesetabilan yang dipengaruhi oleh beberapa faktor yaitu gaya penahan dan gaya penggerak yang bekerja dalam kesetabilan lereng tersebut. Gaya-gaya yang bekerja pada lereng secara umum dapat dikelompokkan menjadi dua yaitu gaya-gaya yang cenderung untuk menyebabkan material pada lereng untuk bergerak ke bawah dan gaya-gaya yang menahan material pada lereng sehingga tidak terjadi pergerakan atau longsoran.

Ketika gaya penahan lebih besar dari gaya penggeraknya, maka lereng tersebut akan berada dalam keadaan stabil, jika gaya penahan lebih kecil dari gaya pendorong maka lereng tersebut akan longsor. Untuk menyatakan nilai (tingkat) kestabilan suatu lereng dikenal istilah yang disebut dengan nilai faktor keamanan (safety factor), yang merupakan hasil perbandingan antara besarnya gaya penahan terhadap gaya penggerak longsoran, dan dinyatakan sebagai berikut:

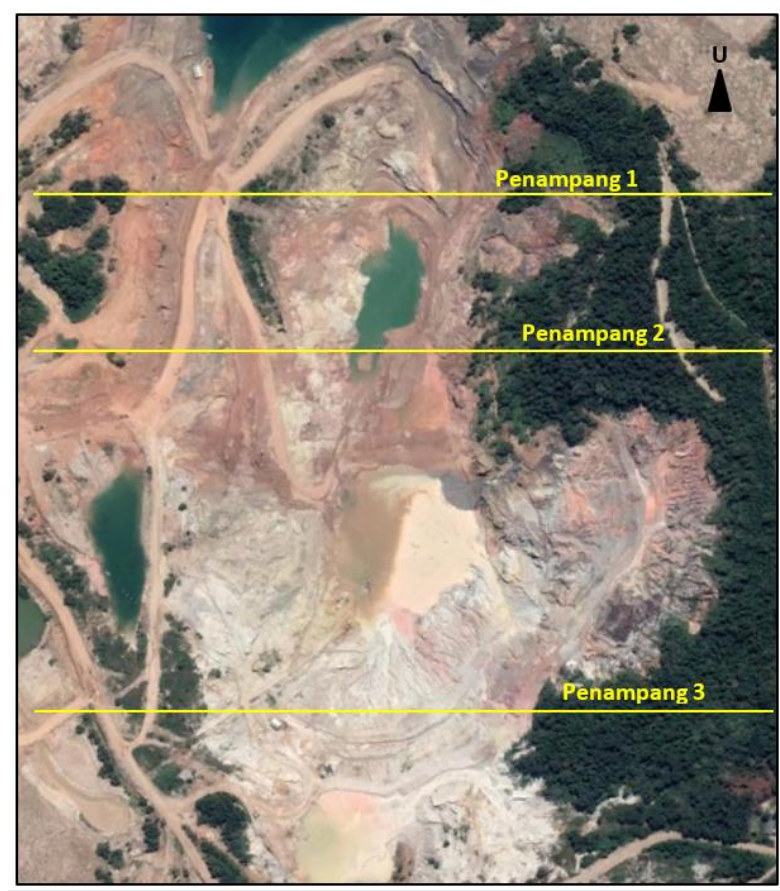

Gambar 3. Peta penampang analisis site Pemali. 


\section{Faktor-Faktor yang Memperbesar Gaya Penggerak}

Dalam Nurhidayat, (2016) Penambahan beban / gaya penggerak juga dapat membuat lereng yang pada mulanya stabil menjadi tidak stabil. Penambahan ini juga dapat terjadi secara alamiah ataupun karena aktivitas manusia.

\section{Penambahan Air Tanah}

Penambahan air tanah pada pori-pori atau celah-celah tanah dan/atau batuan jelas akan menambah berat satuan material memperbesar beban pada lereng. Maka akan memperbesar gaya penggerak yang dapat mengakibatkan longsor pada lereng.

\section{Aktivitas Tektonik}

Terjadinya pergerakan seperti pergeseran, pengangkatan atau penurunan muka bumi akan mengakibatkan terjadinya perubahan arah dan besar gaya-gaya yang bekerja pada suatu titik tetentu di muka bumi. Dengan begitu geometri akan berubah dan beban pada lerenglereng yang baru akan lebih besar sehingga dapat mengakibatkan ketidakstabilan pada lereng.

\section{Vibrasi atau Getaran}

Getaran atau gelombang kejut dapat menghasilkan energi besar, contohnya peledakan (blasting), yang apabila mempunyai arah yang sama dengan permukaan suatu lereng dapat menambah beban dan mengakibatkan terjadinya longsoran.

\section{Penambahan Beban Akibat Penimbunan}

Timbunan material di atas suatu lereng akan memberikan beban lebih terhadap lereng, sehingga memperbesar gaya penggerak dan dapat mengakibatkan longsoran pada lereng tersebut.

\section{B. METODOLOGI}

Penelitian dilakukan dengan cara mengumpulkan data sekunder dan proses analisis dengan perangkat lunak. Data sekunder yang dikumpulkan berupa batuan inti pemboran site Pemali, geometri lereng aktual dan data parameter hasil pengeboran geoteknik. Data hasil pengeboran berupa hasil uji sifat fisik dan uji sifat mekanik (uji triaksial dan uji geser langsung). Hasil uji sifat fisik mendapatkan data kandungan air, spesifik gravity, densitas natural, densitas kering dan saturasi. Uji sifat mekanik mendapatkan data uniaxial compressive strength, kohesi dan sudut gesek dalam. Pengeboran geoteknik dilakukan pada 4 titik. Potongan melintang yang digunakan untuk analisis lereng sebanyak 3 buah dan posisinya dekat dengan titik pengeboran. Proses analisis juga akan memasukkan parameter muka air tanah dan skenario desain beberapa overall slope angle

Proses analisis dilakukan dengan menggunakan perpaduan antara metode deterministik dan probabilistik. Metode deterministik akan memberikan nilai faktor keamanan (FK) sebagai acuan dalam penentuan kestabilan lereng. Karena adanya variasi parameter mekanik maupun fisik dari material pembentuk lereng, sehingga metode probabilistik juga digunakan. Penelitian ini menghasilkan nilai factor of safety (FS), probability of failure (PF) dan reliability index (RI) dari beberapa skenario overall slope angle.

Banyak sekali metode yang digunakan dalam analisis kestabilan lereng. Pada penelitian ini menggunakan menggunakan metode Bishop yang merupakan pengembangan dari metode irisan biasa. Karena gaya interaksi normal antara irisan yang berdekatan diasumsikan collinear (berhimpitan) dan resultan gaya geser antar potongan adalah nol. Nilai faktor keamanan dapat dihasilkan sebagai keluaran (output) dari metode Bishop. 


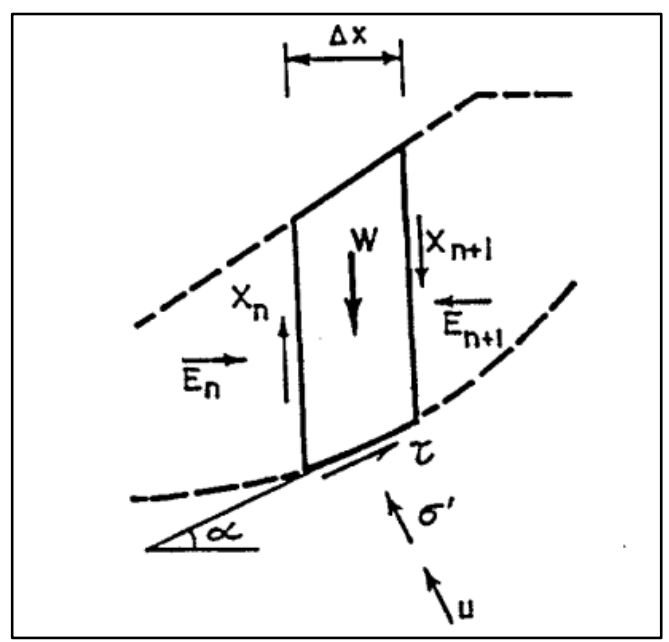

Gambar 4. Gaya dan tegangan yang bekerja pada potongan

Faktor keamanan untuk kesetimbangan momen pada metode Bishop (1960) adalah:

$$
\mathrm{F}=\frac{\sum\left[c^{\prime} \Delta X \sec \alpha+N^{\prime} \tan \theta\right]}{\sum W \sin \alpha}
$$

Keterangan :

$$
\begin{array}{ll}
\mathrm{c}^{\prime} & : \text { Kohesi } \\
\Delta \mathrm{x} & : \text { Lebar potongan } \\
\mathrm{W} & : \text { Berat dari potongan } \\
\mathrm{N} & : \mathrm{N}-\mathrm{U} \\
\mathrm{N} & : \text { W } \cos \alpha \\
\mathrm{U} & : \text { Gaya tekanan pori } \\
\theta & : \text { Sudut gesek } \\
\alpha & : \text { Inklinasi dari dasar potongan }
\end{array}
$$

Analisis probabilistik berbeda dengan analisis deterministik. Analisis probabilistik dikembangkan untuk mengatasi persoalan ketidakpastian dan variasi pada sifat material. Karena input dari material penyusun lereng seperti kohesi, densitas tanah dan lain-lain mempunyai nilai yang berbeda-beda (nilai variasi cukup tinggi). Hal ini berlaku pada material pembentuk lereng Tambang Pemali. Umumnya terdapat 3 jenis metode probabilistik yang umum digunakan adalah FOSM (First-Order, Second Moment), Rosenblueth (Point Estimates) dan Monte Carlo. Pada penelitian ini, metode yang digunakan adalah metode Monte Carlo.

Metode Monte Carlo adalah algoritma berhitung dan digunakan dalam persoalan optimisasi, integrasi numerik dan menghasilkan output dari distribusi probabilitas. Metode Monte Carlo menetapkan fungsi distribusi probabilitas dari nilai input. Metode Monte Carlo juga mengadopsi distribusi normal dalam perhitungannya. Output yang dihasilkan metode Monte Carlo adalah distribusi nilai dari factor of safety (FS). Tetapi, metode Monte Carlo juga mempunyai kekurangan seperti membutuhkan waktu yang relatif lama dan proses komputasi yang berat.

\section{HASIL DAN PEMBAHASAN}

Berdasarkan hasil pemboran Geoteknik, penulis mengelompokkan litologi penyusun tambang pemali menjadi 4 satuan untuk digunakan dalam analisis kestabilan lereng tambang yaitu Sekis mika, Metasedimen, Granit lapuk dan Granit. 


\section{Geologi daerah Penelitian}

Dari hasil penelitian lapangan berdasarkan pemetaan geologi dan empat pemboran geoteknik. Litologi yang terdapat di daerah penelitian adalah Sekis mika, batulempung, hornfels, black shale, granit lapuk, dan granit

\section{Geoteknik daerah penelitian}

Aspek geoteknik yang akan dibahas adalah sifat fisik dan sifat mekanika tanah/batuan terhadap kondisi kestabilan lereng tambang yang dituangkan kedalam hasil perhitungan nilai Faktor Keamanan (FS)

\section{Sifat Fisik dan Mekanika}

Hasil pengeboran geoteknik digunakan penulis sebagai data utama dalam analisis kestabilan lereng tambang. Parameter sifat fisik dan mekanik yang digunakan pada analisis ini didapat dari statistika deskriptif pada empat satuan. Data ini dapat dilihat pada Tabel 1. Parameter tersebut kemudian dijadikan nilai untuk dilakukan analisis kestabilan lereng tambang.

Tabel 1. Sifat fisik dan mekanik satuan litologi

\begin{tabular}{rlllllrlrrrr}
\hline \multirow{2}{*}{ No } & \multirow{2}{*}{ Satuan } & \multicolumn{3}{c}{ Berat Jenis $\left(\mathbf{k N} / \mathbf{m}^{\mathbf{3}}\right)$} & \multicolumn{3}{c}{ Kohesi $\left(\mathbf{k N} / \mathbf{m}^{\mathbf{2}}\right)$} & \multicolumn{3}{c}{ Sudut Geser Dalam $\left(^{\mathbf{0}}\right)$} \\
& Litologi & Rentang & Mean & SD & \multicolumn{1}{c}{ Rentang } & \multicolumn{1}{c}{ Mean } & SD & Rentang & Mean & SD \\
\hline \multirow{2}{*}{1} & Sekis Mika & $14,91-21,28$ & 18,07 & 0,12 & $9,81-78,94$ & 38,05 & 0,16 & $1,62-24,79$ & 17,24 & 3,85 \\
2 & Metasedimen & $16,77-27,49$ & 25,16 & 0,27 & $41,78-810,10$ & 437,29 & 2,48 & $20,18-50,15$ & 43,61 & 6,13 \\
3 & Granit Lapuk & $16,87-26,74$ & 22,72 & 0,35 & $19,81-902,21$ & 169,27 & 2,42 & $10,32-47,24$ & 26,03 & 14,10 \\
4 & Granit & $23,25-26,58$ & 25,97 & 0,07 & $75,51-721,77$ & 404,98 & 2,04 & $34,11-50,23$ & 41,99 & 4,92 \\
\hline
\end{tabular}

\section{Klasifikasi Kestabilan Lereng}

Kriteria desain dari potongan lereng yang stabil harus dicapai melalui simulasi dan iterasi dalam proses stabilitas lereng analisis. Sebagai pedoman lereng dalam keadaan mantap diambil angka FS minimum berdasarkan kriteria Kepmen ESDM No. 1827 K/30/MEM/2018 tentang "Pedoman Pelaksanaan Kaidah Teknik Pertambangan yang Baik”

Tabel 2. Kriteria kestabilan lereng tambang (modifikasi Kepmen No. 1827 K/30/2018)

\begin{tabular}{|c|c|c|c|c|}
\hline \multirow[b]{2}{*}{ Jenis Lereng } & \multirow{2}{*}{$\begin{array}{c}\text { Keparahan } \\
\text { Longsor } \\
\text { (Consequences } \\
\text { of Failure/CoF) }\end{array}$} & \multicolumn{3}{|c|}{$\begin{array}{l}\text { Kriteria dapat diterima } \\
\text { (Acceptance Criteria) }\end{array}$} \\
\hline & & $\begin{array}{l}\text { Faktor } \\
\text { Keamanan } \\
\text { (FK) Statis } \\
\text { (Min) }\end{array}$ & $\begin{array}{l}\text { Faktor Keamanan } \\
\text { (FK) Dinamis (Min) }\end{array}$ & $\begin{array}{c}\text { Probabilitas Longsor } \\
\text { (Probability of Failure) } \\
\text { (Maks) PoF }(\mathrm{FK} \leq 1)\end{array}$ \\
\hline $\begin{array}{l}\text { Lereng } \\
\text { tunggal }\end{array}$ & $\begin{array}{l}\text { Rendah s.d. } \\
\text { Tinggi }\end{array}$ & 1.1 & Tidak Ada & $25-50 \%$ \\
\hline \multirow{3}{*}{ Inter-ramp } & Rendah & $1.15-1.2$ & 1 & $25 \%$ \\
\hline & Menengah & $1.2-1.3$ & 1 & $20 \%$ \\
\hline & Tinggi & $1.2-1.3$ & 1.1 & $10 \%$ \\
\hline \multirow{3}{*}{$\begin{array}{l}\text { Lereng } \\
\text { Keseluruhan }\end{array}$} & Rendah & $1.2-1.3$ & 1 & $15 \%-20 \%$ \\
\hline & Menengah & 1.3 & 1.05 & $10 \%$ \\
\hline & Tinggi & $1.3-1.5$ & 1.1 & $5 \%$ \\
\hline
\end{tabular}

\section{Kestabilan Lereng}

Analisis kestabilan lereng dibuat dengan asumsi target penambangan sampai kedalaman 150 meter. Analisis dibuat dengan kondisi statis dan dinamis (seismic load). Analisis kestabilan lereng ini berdasarkan pada keadaan muka air tanah kedalaman 5 meter dan kondisi dewatering dengan 
kedalaman muka air tanah pada elevasi 15 mdpl. Dengan memperhitungkan koefisien getaran dari gempa maupun alat berat bertujuan untuk mengantisipasi kondisi terburuk ketika terjadi gempa.

Tabel 3. Nilai faktor kestabilan lereng penampang 1 kondisi MAT alami

\begin{tabular}{ccccccc}
\hline $\begin{array}{c}\text { Sudut } \\
\text { Lereng }\end{array}$ & FS & Statis & & \multicolumn{3}{c}{ Dinamis } \\
& PF (\%) & RI & FS & PF (\%) & RI \\
\hline 40 & 0.375 & 100 & -20.695 & 0.371 & 100 & -23.706 \\
35 & 0.426 & 100 & -17.191 & 0.418 & 100 & -17.769 \\
30 & 0.564 & 100 & -8.877 & 0.551 & 100 & -9.31 \\
25 & 0.932 & 76.9 & -0.764 & 0.909 & 84.9 & -1.054 \\
20 & 1.073 & 29.5 & 0.547 & 1.037 & 38.3 & 0.284 \\
15 & 1.422 & 1.4 & 2.315 & 1.363 & 2.4 & 2.075 \\
\hline
\end{tabular}

Tabel 4. Nilai faktor kestabilan lereng penampang 1 kondisi MAT Dewatering

\begin{tabular}{ccccccc}
\hline $\begin{array}{c}\text { Sudut } \\
\text { Lereng }\end{array}$ & FS & Statis & & \multicolumn{3}{c}{ Dinamis } \\
& PF (\%) & RI & FS & PF (\%) & RI \\
\hline 40 & 0.543 & 100 & -6.246 & 0.532 & 100 & -6.542 \\
35 & 0.621 & 100 & -4.222 & 0.607 & 100 & -4.476 \\
30 & 0.739 & 100 & -3.03 & 0.723 & 100 & -3.289 \\
25 & 1.248 & 5.9 & 1.586 & 1.216 & 8.1 & 1.419 \\
20 & 1.527 & 1.6 & 2.27 & 1.475 & 2.3 & 2.116 \\
15 & 1.916 & 0.1 & 3.158 & 1.836 & 0.3 & 3.005 \\
\hline
\end{tabular}

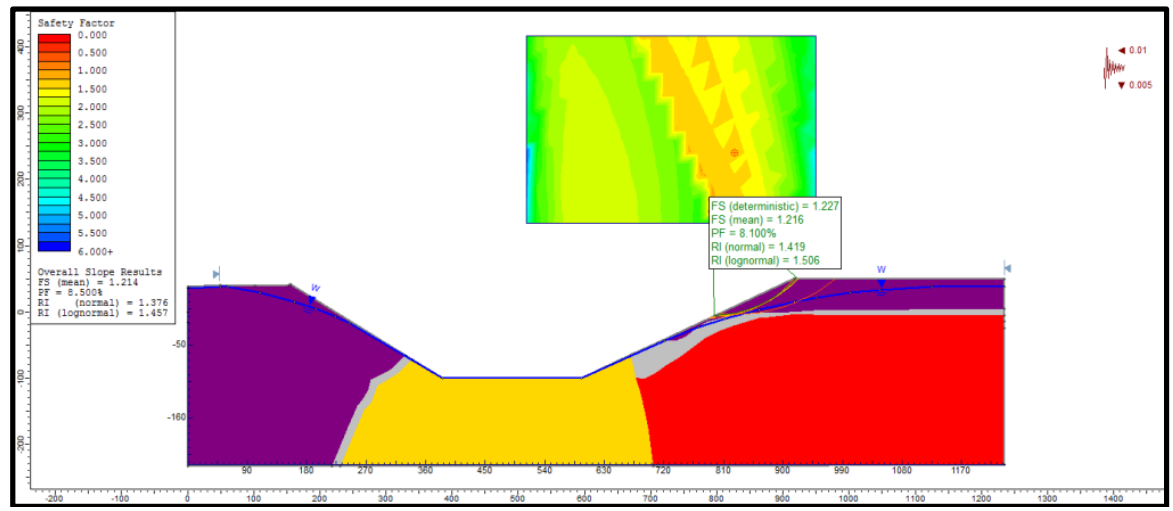

Gambar 5. Simulasi penampang 1 sudut lereng $25^{\circ}$ kodisi dinamis dan dewatering

Hasil analisis kestabilan lereng pada penampang 1 dengan rencana tinggi lereng pit 150 meter dengan kodisi muka air tanah (MAT) alami diperoleh faktor keamanan (FS) statis dari 0,375 sampai 1,422 Probability of Failure (PF) dari 100\% sampai 1,4\% dan nilai Reliability Index (RI) dari -20,695 sampai 2,315. Pada kondisi dinamis diperoleh nilai faktor keamanan (FS) dinamis dari 0,371 sampai 1,363 Probability of Failure (PF) dari 100\% sampai 2,4\% dan nilai Reliability Index (RI) dari -23,706 sampai 2,075. Maka dapat didefinisikan lereng berada pada kondisi kritis pada sudut kemiringan lereng $15^{\circ}-20^{\circ}$ namun berada pada kondisi labil pada sudut kemiringan lereng $25^{\circ}-40^{\circ}$.

Pada kondisi penurunan MAT (dewatering) diperoleh faktor keamanan (FS) statis dari 0,543 sampai 1,916 Probability of Failure (PF) dari 100\% sampai 0,1\% dan nilai Reliability Index (RI) dari -6,246 sampai 3,158. Pada kondisi dinamis diperoleh nilai faktor keamanan (FS) dinamis dari 
0,532 sampai 1,836 Probability of Failure (PF) dari 100\% sampai 0,3\% dan nilai Reliability Index (RI) dari -6,542 sampai 3,005. Maka dapat didefinisikan lereng berada pada kondisi kritis pada sudut kemiringan lereng $15^{\circ}-25^{\circ}$ namun berada pada kondisi labil pada sudut kemiringan lereng $30^{\circ}-40^{\circ}$.

Tabel 5. Nilai faktor kestabilan lereng penampang 2 kondisi MAT alami

\begin{tabular}{ccccccc}
\hline $\begin{array}{c}\text { Sudut } \\
\text { Lereng }\end{array}$ & FS & $\begin{array}{c}\text { Statis } \\
\text { PF }(\%)\end{array}$ & RI & FS & PF $(\%)$ & RI \\
\hline 50 & 0.594 & 100 & -8.129 & 0.584 & 100 & -8.494 \\
45 & 0.798 & 100 & -2.836 & 0.784 & 100 & -3.096 \\
40 & 1.151 & 7.4 & 1.451 & 1.128 & 10.4 & 1.257 \\
35 & 1.372 & 0 & 3.351 & 1.343 & 0 & 3.14 \\
30 & 1.63 & 0 & 4.065 & 1.529 & 0 & 3.876 \\
25 & 1.884 & 0 & 5.092 & 1.835 & 0 & 4.767 \\
\hline
\end{tabular}

Tabel 6. Nilai faktor kestabilan lereng penampang 2 kondisi MAT Dewatering

\begin{tabular}{ccccccc}
\hline $\begin{array}{c}\text { Sudut } \\
\text { Lereng }\end{array}$ & FS & $\begin{array}{c}\text { Statis } \\
\text { PF }(\%)\end{array}$ & RI & FS & PF $(\%)$ & RI \\
\hline 50 & 0.708 & 100 & -3.905 & 0.697 & 100 & -4.134 \\
45 & 0.863 & 94.2 & -1.604 & 0.848 & 96.8 & -1.816 \\
40 & 1.154 & 7.1 & 1.469 & 1.131 & 10 & 1.276 \\
35 & 1.473 & 0 & 3.714 & 1.44 & 0 & 3.535 \\
30 & 1.766 & 0 & 4.631 & 1.722 & 0 & 4.451 \\
25 & 1.99 & 0 & 5.137 & 1.934 & 0 & 4.966 \\
\hline
\end{tabular}

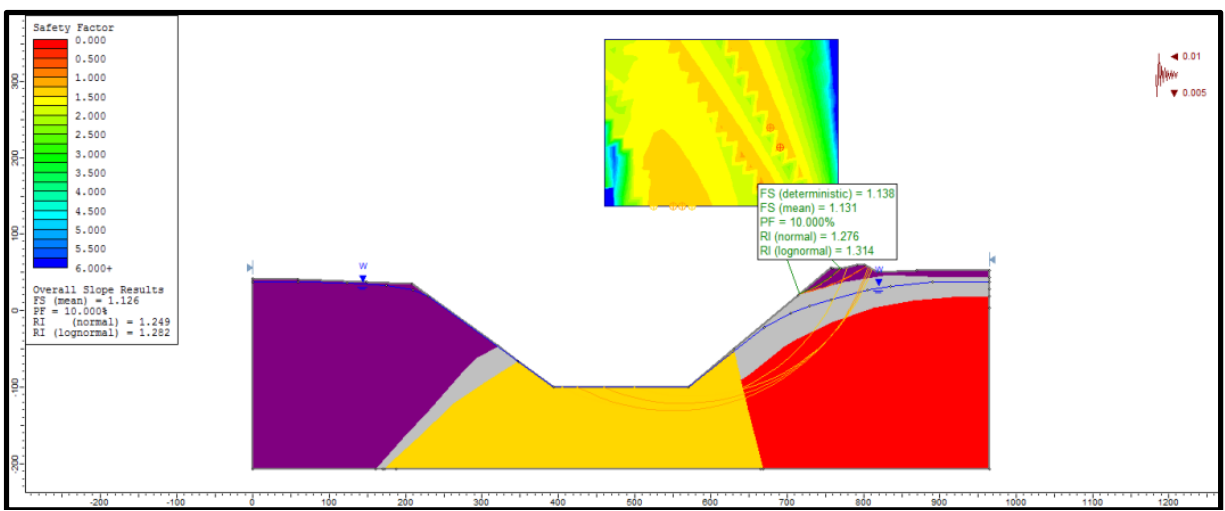

Gambar 6. Simulasi penampang 2 sudut lereng $40^{\circ}$ kodisi dinamis dan dewatering

Hasil analisis kestabilan lereng pada penampang 2 dengan rencana tinggi lereng pit 150 meter dengan kodisi muka air tanah (MAT) alami diperoleh faktor keamanan (FS) statis dari 0,594 sampai 1,884 Probability of Failure (PF) dari 100\% sampai 0\% dan nilai Reliability Index (RI) dari -8,129 sampai 5,092. Pada kondisi dinamis diperoleh nilai faktor keamanan (FS) dinamis dari 0,584 sampai 1,835 Probability of Failure (PF) dari 100\% sampai 0\% dan nilai Reliability Index (RI) dari -8,494 sampai 4,767. Maka dapat didefinisikan lereng berada pada kondisi kritis pada sudut kemiringan lereng $25^{\circ}-40^{\circ}$ namun berada pada kondisi labil pada sudut kemiringan lereng $45^{\circ}-50^{\circ}$.

Pada kondisi penurunan MAT (dewatering) diperoleh faktor keamanan (FS) statis dari 0,708 sampai 1,99 Probability of Failure (PF) dari 100\% sampai 0\% dan nilai Reliability Index (RI) dari $-3,905$ sampai 5,137. Pada kondisi dinamis diperoleh nilai faktor keamanan (FS) dinamis dari 
0,697 sampai 1,934 Probability of Failure (PF) dari 100\% sampai 0\% dan nilai Reliability Index (RI) dari -4,134 sampai 4,966. Maka dapat didefinisikan lereng berada pada kondisi kritis pada sudut kemiringan lereng $25^{\circ}-40^{\circ}$ namun berada pada kondisi labil pada sudut kemiringan lereng $45^{\circ}-50^{\circ}$.

Tabel 7. Nilai faktor kestabilan lereng penampang 3 kondisi MAT alami

\begin{tabular}{ccccccc}
\hline $\begin{array}{c}\text { Sudut } \\
\text { Lereng }\end{array}$ & FS & $\begin{array}{c}\text { Statis } \\
\text { PF }(\%)\end{array}$ & RI & FS & PF $(\%)$ & RI \\
\hline 40 & 0.533 & 100 & -3.802 & 0.523 & 100 & -3.963 \\
35 & 0.568 & 99.5 & -3.183 & 0.557 & 99.7 & -3.329 \\
30 & 0.661 & 96.7 & -2.162 & 0.647 & 97.4 & -2.296 \\
25 & 0.792 & 83.6 & -0.956 & 0.774 & 85.4 & -1.064 \\
20 & 1.049 & 49.5 & 0.167 & 1.019 & 54 & 0.068 \\
15 & 1.522 & 10.7 & 1.162 & 1.46 & 13.5 & 1.091 \\
\hline
\end{tabular}

Tabel 8. Nilai faktor kestabilan lereng penampang 3 kondisi MAT Dewatering

\begin{tabular}{ccccccc}
\hline $\begin{array}{c}\text { Sudut } \\
\text { Lereng }\end{array}$ & FS & Statis & & \multicolumn{3}{c}{ Dinamis } \\
\hline 40 & 0.648 & 96.3 & -2.101 & 0.635 & 97.1 & -2.221 \\
35 & 0.638 & 97 & -2.227 & 0.625 & 97.8 & -2.35 \\
30 & 0.752 & 86.5 & -1.136 & 0.736 & 88.3 & -1.236 \\
25 & 0.925 & 65.3 & -0.281 & 0.902 & 67.9 & -0.372 \\
20 & 1.203 & 32.3 & 0.502 & 1.168 & 36 & 0.493 \\
15 & 1.525 & 10.6 & 1.166 & 1.469 & 13.7 & 1.079 \\
\hline
\end{tabular}

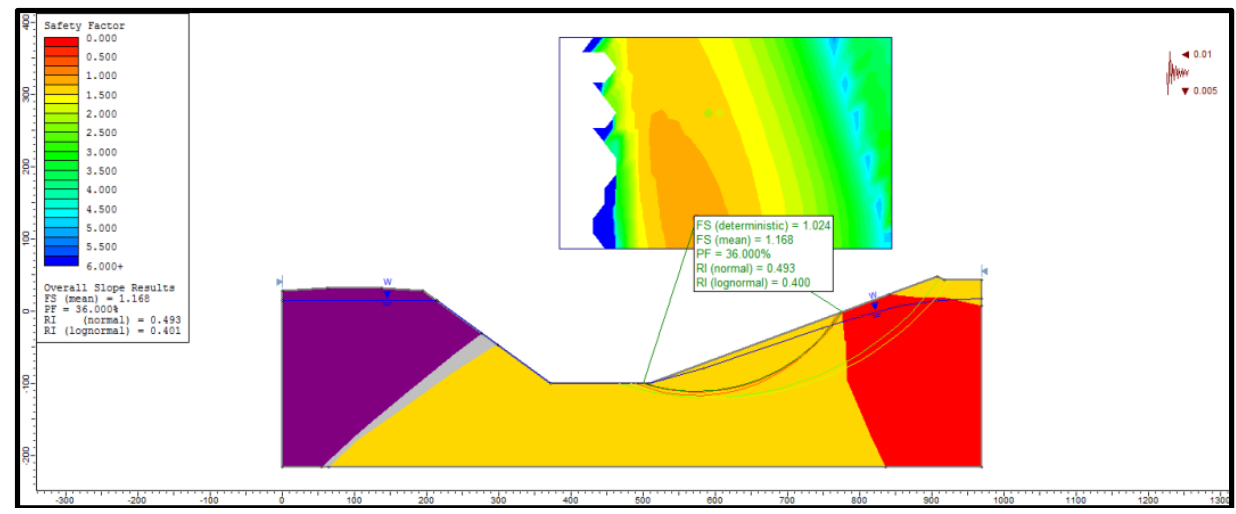

Gambar 7. Simulasi penampang 3 sudut lereng $20^{\circ}$ kodisi dinamis dan dewatering

Hasil analisis kestabilan lereng pada penampang 3 dengan rencana tinggi lereng pit 150 meter dengan kodisi muka air tanah (MAT) alami diperoleh faktor keamanan (FS) statis dari 0,533 sampai 1,522 Probability of Failure (PF) dari 100\% sampai 10,7\% dan nilai Reliability Index (RI) dari -3,802 sampai 1,162. Pada kondisi dinamis diperoleh nilai faktor keamanan (FS) dinamis dari 0,523 sampai 1,46 Probability of Failure (PF) dari 100\% sampai 13,5\% dan nilai Reliability Index (RI) dari -3,963 sampai 1,091. Maka dapat didefinisikan lereng berada pada kondisi kritis pada sudut kemiringan lereng $15^{\circ}-20^{\circ}$ namun berada pada kondisi labil pada sudut kemiringan lereng $25^{\circ}-40^{\circ}$.

Pada kondisi penurunan MAT (dewatering) diperoleh faktor keamanan (FS) statis dari 0,648 sampai 1,525 Probability of Failure (PF) dari 96,3\% sampai 10,6\% dan nilai Reliability Index (RI) dari -2,101 sampai 1,166. Pada kondisi dinamis diperoleh nilai faktor keamanan (FS) dinamis dari 
0,635 sampai 1,469 Probability of Failure (PF) dari 97,1\% sampai 13,7\% dan nilai Reliability Index (RI) dari -2,221 sampai 1,079. Maka dapat didefinisikan lereng berada pada kondisi kritis pada sudut kemiringan lereng $15^{\circ}-20^{\circ}$ namun berada pada kondisi labil pada sudut kemiringan lereng $25^{\circ}-40^{\circ}$.

\section{KESIMPULAN}

Satuan litologi penyusun site Pemali terdiri dari batuan granit, metasedimen, batuan sedimen, dan alluvium kemudian dikelompokkan menjadi empat satuan geoteknik yaitu satuan sekis mika, satuan metasedimen, satuan granit lapuk dan satuan granit.

Berdasarkan hasil simulasi analisis kestabilan lereng tambang dapat disimpulkan bahwa pada penampang 1 lereng dengan rencana tinggi lereng pit 150 meter dikategorikan aman dengan geometri sudut lereng keseluruhan tidak lebih dari $15^{\circ}$ pada kondisi muka air tanah alami yang memiliki nilai FS 1,363 PF 2,4\% RI 2,075 dan dikategorikan aman dengan sudut lereng keseluruhan tidak lebih dari $25^{\circ}$ pada kondisi dewatering yang memiliki nilai FS 1,216 PF 8,1\% RI 1,419. Pada penampang 2 dikategorikan aman dengan geometri sudut lereng keseluruhan tidak lebih dari $40^{\circ}$ pada kondisi muka air tanah alami yang memiliki nilai FS 1,128 PF 10,4\% RI 1,257 dan dikategorikan aman dengan sudut lereng keseluruhan tidak lebih dari $40^{\circ}$ pada kondisi dewatering yang memiliki nilai FS 1,131 PF 10\% RI 1,276. Pada penampang 3 dikategorikan aman dengan geometri sudut lereng keseluruhan tidak lebih dari $15^{\circ}$ pada kondisi muka air tanah alami yang memiliki nilai FS 1,46 PF 13,5\% RI 1,091 dan dikategorikan aman dengan sudut lereng keseluruhan tidak lebih dari $20^{\circ}$ pada kondisi dewatering yang memiliki nilai FS 1,168 PF 36\% RI 0,493 .

Pada semua penampang menunjukkan nilai faktor keamanan yang lebih tinggi dengan adanya penurunan muka air tanah (dewatering) dibandingkan dengan kondisi muka air tanah alami karena air pada pori batuan akan menambah berat pada satuan material dan menambah beban pada lereng yang akan menambah gaya penggerak pada lereng tambang yang dapat mengakibatkan longsor pada lereng. Pada Penampang 2 memiliki geometri sudut lereng tambang lebih curam dibandingkan penampang lainnya karena litologi penyusun pada penampang tersebut tersusun atas satuan granit dan satuan metasedimen yang memiliki sifat fisik dan mekamik yang lebih stabil sehingga sudut lereng tambang yang dihasilkan lebih curam dibandingkan penampang lereng lainnya.

\section{E. SARAN}

Dalam menentukan rekomendasi geometri lereng bukaan tambang diperlukan nilai faktor keamanan (FS) yang kritis sampai stabil dan memperhatikan nilai Probability of Failure (PF) dan Reliability Index (RI) pada kondisi muka air tanah alami maupun kondisi dewatering serta perlu dipertimbangkan kestabilan lereng tambang pada kondisi statis dan dinamis akibat faktor gempa, getaran dari peledakan dan getaran akibat aktivitas alat berat.

\section{PUSTAKA}

Anonim, 2018, Pedoman Pelaksanaan Kaidah Teknik Pertambangan yang Baik. Jakarta: Kepmen ESDM No. 1827 K/30/MEM/2018 hal. 57.

Bishop, A.W and Morgenstern, N. (1960): Stability coefficient for earth slopes. Geotechnique, Vol. 10. The Institution of Civil Engineers.

Huvaj, Nejan and Oguz, A., Emir. (2018): Probabilistic Slope Stability Analysis : A Case Study, Sakarya University Journal of Science. 
Mangga, S. Andi dan B. Djamal. (1994): Peta Geologi Lembar Bangka Utara Sumatera, Pusat Penelitian dan Pengembangan Geologi Skala 1:250.000.

Nurhidayat, T. R.I. Sophian dan Z. Zakaria. (2016): Influence Groundwater Levels to Safety Factor of Slope Mining Case Study: Area " $X$ ”, South Sumatera Province, Indonesia. Bandung : Seminar Nasional ke III Fakultas Teknik Geologi Universitas Padjadjaran no.1.20.

Queiroz, I. M. (2016): Comparison between Deterministic and Probabilistic Stability Analysis, Featuring Consequent Risk Assessment, International Journal of Geotechnical and Geological Engineering Vol:10, No:6, 2016.

Wijayanti, K., Pratama, D.Y., Muslim, D., Sophian, I. and Zakaria, Z. (2015): The Analysis of The Slope Stability Design on Pemali, North Bangka, Bangka Belitung Islands, Indonesia, $10^{\text {th }}$ Asian Regional Conference of IAEG. 
PROSIDING TPT XXVIII PERHAPI 2019 